\title{
Responses of Spinach to Salinity and Nutrient Deficiency in Growth, Physiology, and Nutritional Value
}

\author{
Chenping $\mathrm{Xu}^{1}$ and Beiquan Mou \\ U.S. Department of Agriculture, Agricultural Research Services, 1636 East Alisal Street, Salinas, \\ CA 93905
}

\begin{abstract}
Additional INDEX words. Spinacia oleracea, antioxidant, nitrogen, phosphorus, phytochemicals, potassium
Abstract. Salinity and nutrient-depleted soil are major constraints to crop production, especially for vegetable crops. The effects of salinity and nutrient deficiency on spinach (Spinacia oleracea $\mathrm{L}$.) were evaluated in sand cultures under greenhouse conditions. Plants were watered every day with Hoagland nutrition solution, deprived of nitrogen (N), phosphorous (P), or potassium (K) for nutrient deficiency, either with or without 20/10 mm sodium chloride (NaCl)/ calcium chloride $\left(\mathrm{CaCl}_{2}\right)$ for salinity treatment. Salinity significantly decreased shoot fresh weight (FW) and dry weight (DW), leaf relative water content (RWC), and specific leaf area (SLA) relative to controls after 4 weeks of treatment and increased chlorophyll content, maximum photochemical efficiency $\left(F_{v} / F_{m}\right)$, and photochemical yield [Y(II)]. Nitrogen deficiency greatly reduced shoot FW and DW, SLA, and chlorophyll content, regardless of salt treatment. $Y(I I)$ and $F_{v} / F_{m}$ were reduced by $N$ deficiency and salinity treatment. Phosphorous and $K$ deficiencies, similarly, decreased shoot FW and DW irrespective of salinity treatment and increased chlorophyll content without salt stress. Phosphorous deficiency increased $Y\left(\right.$ II) under control and $F_{v} / F_{m}$ under both control and salt treatment. Salinity and nutrient deficiency also affected the nutritional value of spinach. Salt stress increased carotenoid and flavonoid contents, and reducing power in full-strength Hoagland solution, and decreased leaf ferrous ion chelating ability (FICA). Nutrient deficiency increased reducing power regardless of salinity treatment. Nitrogen deficiency increased anthocyanin and total phenolic contents, decreased carotenoids and flavonoids regardless of salinity treatment, and increased antioxidant capacity under no-salt conditions. Phosphorous deficiency increased carotenoid and flavonoid contents under no-salt condition and enhanced total phenolic content and reduced FICA and amino acid content under salt stress. Potassium deficiency increased total phenolic, carotenoid, and flavonoid contents and antioxidant capacity under non-salt condition, but decreased FICA regardless of salinity treatment. These results suggest that spinach nutritional value could be improved with only moderately or slightly reduced yield through cultural practices that impose either low fertilizer levels or slight salt stress.
\end{abstract}

High-salinity conditions in agricultural soil and irrigation water is one of the most serious challenges faced by agricultural crops in the world. It is estimated that salt-affected soils impact nearly $10 \%$ of the land surface and $50 \%$ of irrigated land in the world (Ruan et al., 2010). The response of plants to salinity is complex and involves changes in morphology, physiology, and metabolism. Salinity effects on plants include cellular water deficit, ion toxicity, nutrient deficiencies, and oxidative stress, leading to growth inhibition, molecular damage, and even plant death (Orcutt and Nilsen, 2000). The global annual losses in agricultural production from salt-affected land are in excess of $\$ 12$ billion and rising (Flowers et al., 2010; Qadir et al., 2008).

Another important limiting factor for crop production is soil nutrient deficiency. Nitrogen is considered the most common deficient nutrient, followed by P and K (Halvin et al., 2005). Nitrogen is a major constituent of proteins, nucleotides, chlorophyll, and many other metabolites and cellular components

Received for publication 17 Aug. 2015. Accepted for publication 20 Oct. 2015. This research was supported by a grant from the California Department of Food and Agriculture Specialty Crop Block Grant Program (SCB13047).

The technical assistance of Phi Diep and critical review by James McCreight and Renee Eriksen are greatly appreciated.

Mention of trade names or commercial products in this publication is solely for the purpose of providing specific information and does not imply recommendation or endorsement by the U.S. Department of Agriculture.

USDA is an equal opportunity provider and employer.

${ }^{1}$ Corresponding author. E-mail: chenping.xu@ars.usda.gov.
(Lawlor, 2002), and thus $\mathrm{N}$ deficiency affects enzyme activities and metabolite content, hastens senescence, causes nucleic acids and proteins to break down, and therefore inhibits plant growth (Crafts-Brandner et al., 1998; Lemaître et al., 2008; Wingler et al., 2006). Phosphorus is a macronutrient of crucial importance in signaling, photosynthesis, and other metabolism (Marschner, 1995). Potassium is an essential nutrient that affects most of the biochemical and physiological processes that influence plant growth and metabolism (Wang et al., 2013).

Spinach is an important leafy green vegetable that contains large quantities of bioactive compounds and nutrients that are not common to most other vegetables, such as $\rho$-coumaric acid derivatives that exhibit strong antioxidant activity and glucuronic acid derivatives of flavonoids (Bergman et al., 2001; Edenharder et al., 2001; Pandjaitan et al., 2005). It was identified as a moderately salt-sensitive vegetable (Shannon and Grieve, 1999). Salt stress reduced spinach germination, root elongation, seedling growth, chlorophyll content and photosynthesis, and increased membrane permeability (Delfine et al., 1998; Downton et al., 1985; Kaya et al., 2002; Robinson et al., 1983). Langdale et al. (1971) reported that the tolerance threshold for spinach is $2.0 \mathrm{dS} \cdot \mathrm{m}^{-1}$, but irrigation with saline water of $4.0 \mathrm{dS} \cdot \mathrm{m}^{-1}$ on sandy soils did not result in yield reduction (Pasternak and De Malach, 1994). Studies in solution cultures have shown that no significant growth reduction occurs up to $\approx 8 \mathrm{dS} \cdot \mathrm{m}^{-1}$ (Osawa, 1963). There is limited information 


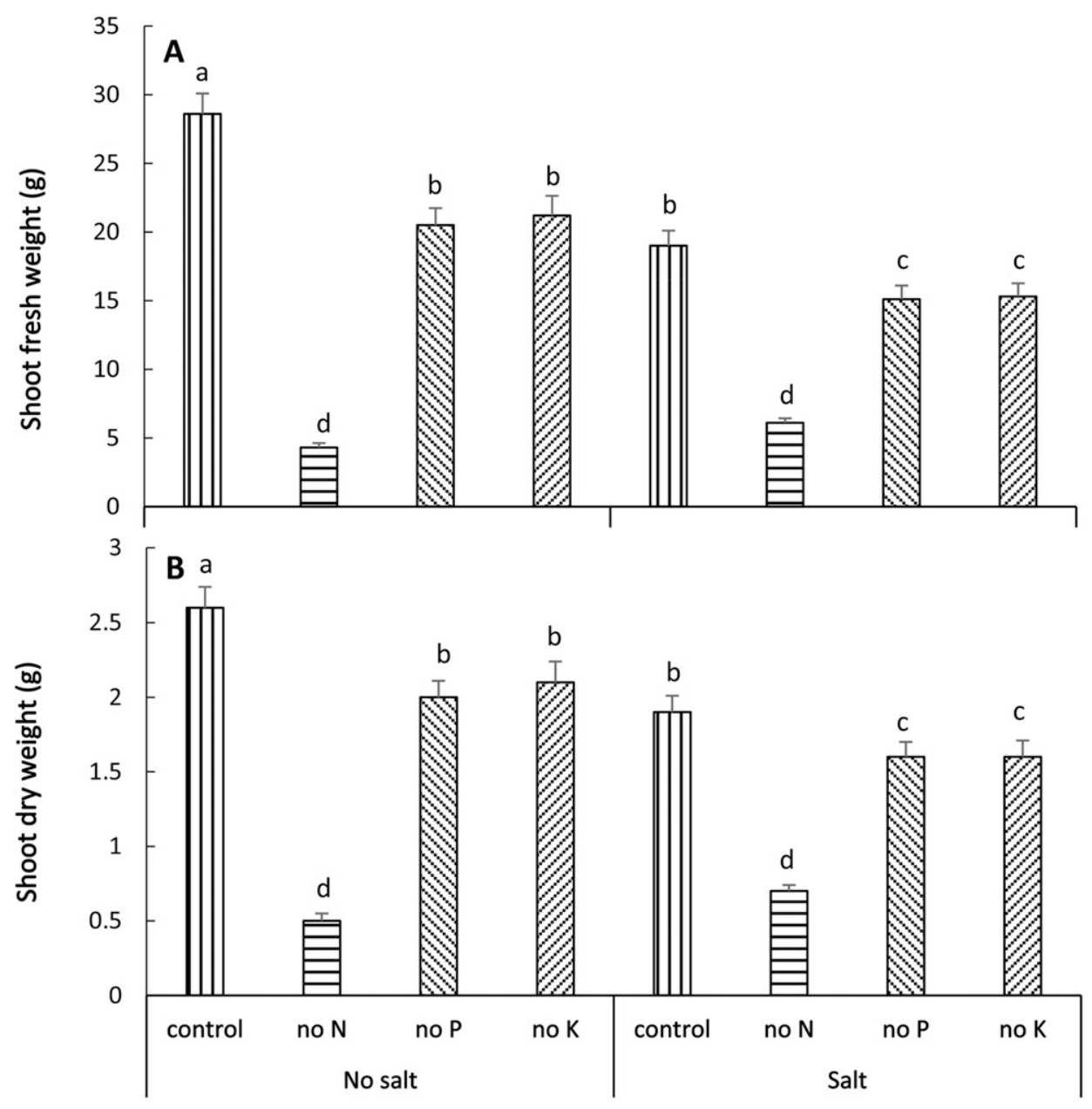

Fig. 1. Effect of salinity and nutrient deficiency on spinach shoot (A) fresh weight and (B) dry weight 4 weeks after treatment. The values are means of eight replicates \pm SE. Different letters on top of bars indicate significant difference at $P \leq 0.05$ according to Student's $t$ test.

about the effects of micronutrient deficiency on spinach growth and physiology. With regard to nutritional quality, previous studies indicated that mild environmental stress or low fertilization could be exploited to enhance nutritional values of vegetable crops. Low N fertilization (Galieni et al., 2015; Stagnari et al., 2015) or environmental stresses, such as salt, heat, chilling, and high light intensity (Oh et al., 2009; PérezLópez et al., 2013), enhanced phenolic content and antioxidant capacity of lettuce (Lactuca sativa L.). Similarly, fruit nutritional value of tomato (Solanum lycopersicum L.) could be improved by low N supply (Bénard et al., 2009) or salt stress (Borghesi et al., 2011). However, literature on spinach nutritional values affected by abiotic stresses is very scarce. The current study aims to assess the effects of salinity and single nutrient $(\mathrm{N}, \mathrm{P}$, or $\mathrm{K})$ deficiency on spinach growth, physiology, and nutritional value.

\section{Materials and Methods}

Plant materials and treatments. Two trials, each with four replications, were conducted from 3 Feb. to 27 Mar. 2015 and $24 \mathrm{Feb}$. to $17 \mathrm{Apr}$. 2015, in a greenhouse located in Salinas, $\mathrm{CA}$ (lat. $36^{\circ} 40^{\prime} 40^{\prime \prime} \mathrm{N}$, long. $121^{\circ} 39^{\prime} 20^{\prime \prime} \mathrm{W}$ ). The average temperature ranged from 12 to $31{ }^{\circ} \mathrm{C}$ and relative humidity ranged from $30 \%$ to $80 \%$. The greenhouse was supplemented with light of a 12-h photoperiod (Sun System 3; Sunlight Supply, Vancouver, WA). The spinach cultivar Crocodile was used in this experiment because the preliminary study indicated that it has middle salt tolerance. For each trial, 2 weeks after seeded in rock wool cells (Grodan Group, Roermond, Netherlands), uniform spinach seedlings were transplanted into plastic pots $(2.3 \mathrm{~L})$ filled with sand. Plants were thinned to one plant per pot and watered every day with fullstrength Hoagland nutrition solution [electrical conductivity $(\mathrm{EC})=2.5$ $\mathrm{dS} \cdot \mathrm{m}^{-1}$ ] (Hoagland and Arnon, 1950).

For each trial, salinity and nutrient treatments were applied $10 \mathrm{~d}$ after transplanting. Salinity stress was induced by adding $10 / 5 \mathrm{~mm} \mathrm{NaCl}$ / $\mathrm{CaCl}_{2}$ into full-strength Hoagland nutrition solution $\left(\mathrm{EC}=4.6 \mathrm{dS} \cdot \mathrm{m}^{-1}\right)$ for $2 \mathrm{~d}$, and then by adding $20 / 10 \mathrm{~mm}$ $\mathrm{NaCl} / \mathrm{CaCl}_{2}$ (final $\mathrm{EC}=6.5 \mathrm{dS} \cdot \mathrm{m}^{-1}$ ). To induce mild salt stress, $20 / 10 \mathrm{~mm}$ $\mathrm{NaCl} / \mathrm{CaCl}_{2}$ was used since preliminary studies indicated that adding $40 / 20 \mathrm{~mm} \mathrm{NaCl} / \mathrm{CaCl}_{2}$ into full-strength Hoagland nutrition solution $\left(\mathrm{EC}=10.2 \mathrm{dS} \cdot \mathrm{m}^{-1}\right)$ for 4 weeks caused $50 \%$ reduction in shoot FW. Exposure of plants to increasing salt concentration allows gradual acclimation of plants to salinity conditions to avoid sudden death of plants at high salt concentration. For N, P, or K deficiency, the sources of N, P, and $\mathrm{K}$ in Hoagland's solution were replaced with alternative chemicals. The $\mathrm{N}$ sources, calcium nitrate $(5 \mathrm{~mm})$ and potassium nitrate $(5 \mathrm{~mm})$, were replaced with $\mathrm{CaCl}_{2}(5 \mathrm{~mm})$ and potassium sulfate $(2.5 \mathrm{~mm})$, respectively. The $\mathrm{P}$ source, potassium dihydrogen orthophosphate $(1 \mathrm{~mm})$, was replaced by potassium sulfate $(0.5 \mathrm{~mm})$. The $\mathrm{K}$ sources, potassium dihydrogen orthophosphate $(1 \mathrm{~mm})$ and potassium nitrate $(5 \mathrm{~mm})$, were replaced with sodium dihydrogen phosphate $(1 \mathrm{~mm})$ and sodium nitrate $(5 \mathrm{~mm})$, respectively. The plants were watered every day for 4 weeks with excess amount of respective solutions to keep the $\mathrm{N}, \mathrm{P}, \mathrm{K}$, and salt contents in sand relatively consistent.

GrowTH AND PHYSIOLOGY MEASUREMENTs. For each trial, 4 weeks after starting the treatment, leaf $\mathrm{F}_{\mathrm{v}} / \mathrm{F}_{\mathrm{m}}$ and $\mathrm{Y}(\mathrm{II})$ were measured with a fluorometer (MINI-PAM-II; Heinz Walz, Effeltrich, Germany) on the first and third leaves from bottom of each plant. Leaf $\mathrm{F}_{\mathrm{v}} / \mathrm{F}_{\mathrm{m}}$ was measured after leaves were adapted in darkness for $30 \mathrm{~min}$.

Leaf discs were collected using a cork borer from the four largest leaves of each plant to measure RWC, SLA, chlorophyll content, and nutritional values. Specific leaf area was calculated 

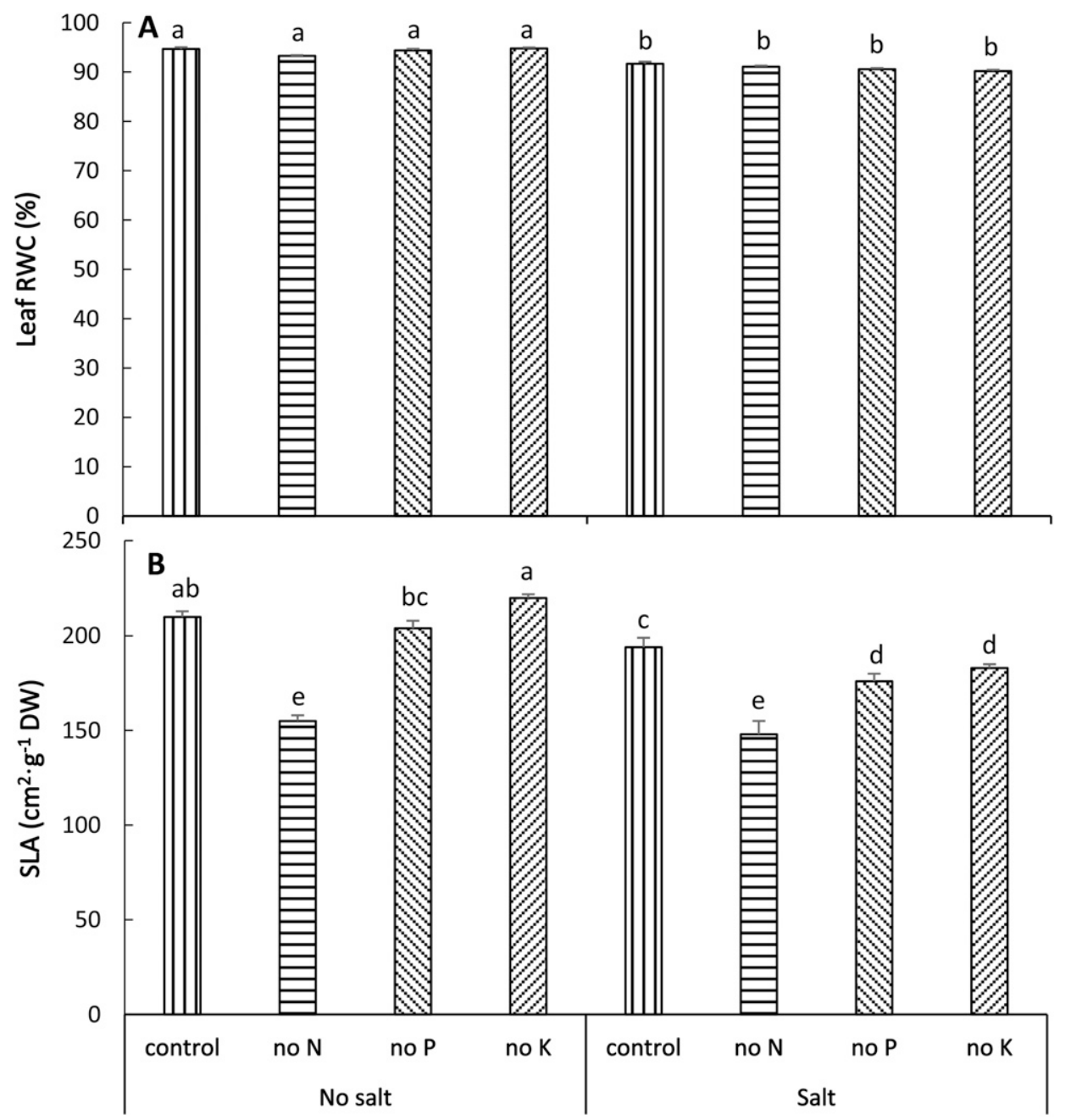

Fig. 2. Effect of salinity and nutrient deficiency on spinach (A) leaf relative water content (RWC) and (B) specific leaf area (SLA) 4 weeks after treatment. The values are means of eight replicates \pm SE. Different letters on top of bars indicate significant difference at $P \leq 0.05$ according to Student's $t$ test.

as $\mathrm{SLA}=$ area/DW, where DW is leaf dry weight after drying at $65^{\circ} \mathrm{C}$ for $3 \mathrm{~d}$ (Evans, 1972). Leaf RWC was calculated as RWC $(\%)=100 \times[(\mathrm{FW}-\mathrm{DW}) /(\mathrm{TW}-\mathrm{DW})]$, where $\mathrm{FW}$ is fresh weight and TW is turgid weight after being soaked in water for $4 \mathrm{~h}$ at $4{ }^{\circ} \mathrm{C}$ (Barr and Weatherley, 1962). Leaf pigments were extracted with methanol, and absorbance of the extraction was measured at 665,652 , and $470 \mathrm{~nm}\left(\mathrm{~A}_{665}, \mathrm{~A}_{652}\right.$, and $\mathrm{A}_{470}$, respectively) with a spectrophotometer (Spectronic Genesys; Spectronic Instruments, Rochester, NY). Chlorophyll a, b and carotenoid contents $\left(\mathrm{C}_{\mathrm{a}}, \mathrm{C}_{\mathrm{b}}\right.$, and $\left.\mathrm{C}_{\mathrm{x}}\right)$ were calculated using the formula described by Lichtenthaler (1987): $\mathrm{C}_{\mathrm{a}}(\mathrm{mg} / \mathrm{L})=$ $16.72 \mathrm{~A}_{665}-9.16 \mathrm{~A}_{652}, \mathrm{C}_{\mathrm{b}}(\mathrm{mg} / \mathrm{L})=34.09 \mathrm{~A}_{652}-15.28 \mathrm{~A}_{665}$, and $\mathrm{C}_{\mathrm{x}}(\mathrm{mg} / \mathrm{L})=\left(1000 \mathrm{~A}_{470}-1.63 \mathrm{C}_{\mathrm{a}}-104.96 \mathrm{C}_{\mathrm{b}}\right) / 221$.

REDUCING POWER AND CONTENTS OF PROTEIN AND AMINO ACID. For analyzing nutritional value, leaf samples were soaked in liquid $\mathrm{N}$ immediately after harvest and stored at $-80{ }^{\circ} \mathrm{C}$. Leaf samples (about $2 \mathrm{~g}$ ) were homogenized in $15 \mathrm{~mL} 0.2 \mathrm{M}$ phosphate buffer $(\mathrm{pH}=6.6)$ using a homogenizer (Polytron; Kinematica, Schweiz, Switzerland). After centrifuging at $9070 g_{\mathrm{n}}$ for $15 \mathrm{~min}$, the supernatant was collected to measure the reducing power and the contents of protein and amino acid. For measuring reducing power, $1.0 \mathrm{~mL}$ extract was mixed with $1.0 \mathrm{~mL}$ of $1 \%$ potassium ferricyanide and was incubated at $50{ }^{\circ} \mathrm{C}$ for $20 \mathrm{~min}$. The reaction was stopped by adding $1.0 \mathrm{~mL}$ of $10 \%$ trichloroacetic acid. After centrifugation at $9070 g_{\mathrm{n}}$ for $10 \mathrm{~min}, 1.0 \mathrm{~mL}$ supernatant was mixed with $1.0 \mathrm{~mL}$ water and $0.2 \mathrm{~mL}$ of $0.1 \%$ ferric chloride. Absorbance at $700 \mathrm{~nm}$ was measured after $1.5 \mathrm{~min}$. A (+)-catechin hydrate served as positive controls (Apetrei et al., 2011).

Amino acid content was determined using the ninhydrin method (Yokoyama and Hiramatsu, 2003). A $1 \% \mathrm{w} / \mathrm{v}$ ninhydrin stock solution was prepared in ethanol containing $0.025 \% \mathrm{w} / \mathrm{v}$ ascorbic acid. A working ninhydrin solution was prepared immediately before use by adding two parts of $0.4 \mathrm{~m}$ sodium acetate buffer ( $\mathrm{pH}$ 5.0) to one part of ninhydrin stock solution. Extract or standard glutamate solution $(100 \mu \mathrm{L})$ was added to $2.9 \mathrm{~mL}$ ninhydrin work solution, and the mixture was heated at $95{ }^{\circ} \mathrm{C}$ for $10 \mathrm{~min}$. The solution was cooled and absorbance at $570 \mathrm{~nm}$ was then measured. Protein content was determined according to the method by Bradford (1976) using bovine serum albumin as standard.

Phytochemical analyses. Phytochemicals were extracted from $\approx 2 \mathrm{~g}$ of sample material with $15 \mathrm{~mL}$ acidified methanol $(1 \% \mathrm{HCl})$ using a homogenizer, then incubated in darkness at $-20{ }^{\circ} \mathrm{C}$ overnight. After centrifuging at $9070 \mathrm{~g}_{\mathrm{n}}$ for $15 \mathrm{~min}$, the supernatant was collected for the analysis of nutrition values. Absorbance of extracts at $530 \mathrm{~nm}$ was measured for total anthocyanin content. Results were expressed as cyanidin-3-glucoside equivalents using a molar extinction coefficient of 29,600 (Connor et al., 2002).

For total phenolic content, $0.1 \mathrm{~mL}$ extract was added to a mixture of $0.15 \mathrm{~mL} \mathrm{H}_{2} \mathrm{O}$ and $0.75 \mathrm{~mL}$ of $1: 10$ diluted FolinCiocalteu reagent (Sigma-Aldrich, St. Louis, MO). After $6 \mathrm{~min}$, $0.60 \mathrm{~mL}$ of $7.5 \%(\mathrm{w} / \mathrm{v}) \mathrm{Na}_{2} \mathrm{CO}_{3}$ was added and vortexed, then the mixture was incubated at $45{ }^{\circ} \mathrm{C}$ in a water bath for $10 \mathrm{~min}$. Samples were allowed to cool to room temperature before reading the absorbance at $765 \mathrm{~nm}$ (Slinkard and Singleton, 1997). A standard curve was prepared from a freshly made gallic acid solution. For total flavonoid content, $0.20 \mathrm{~mL}$ extract was mixed with $0.85 \mathrm{~mL}$ distilled water and $50 \mu \mathrm{L}$ of $5 \% \mathrm{NaNO}_{2}$. After $6 \mathrm{~min}, 100 \mu \mathrm{L}$ of $10 \% \mathrm{AlCl}_{3} \cdot 6 \mathrm{H}_{2} \mathrm{O}$ was added and after another $5 \mathrm{~min}, 0.35 \mathrm{~mL}$ of $1 \mathrm{M} \mathrm{NaOH}$ and $0.20 \mathrm{~mL}$ distilled water were added. The absorbance was measured immediately at $510 \mathrm{~nm}$ (Dewanto et al., 2002). A (+)-catechin hydrate equivalents standard curve was prepared from a freshly made solution.

Total antioxidant capacity was measured by the method of 2,2-diphenyl-1-picrylhydrazyl radical (DPPH) (Brand-Williams 

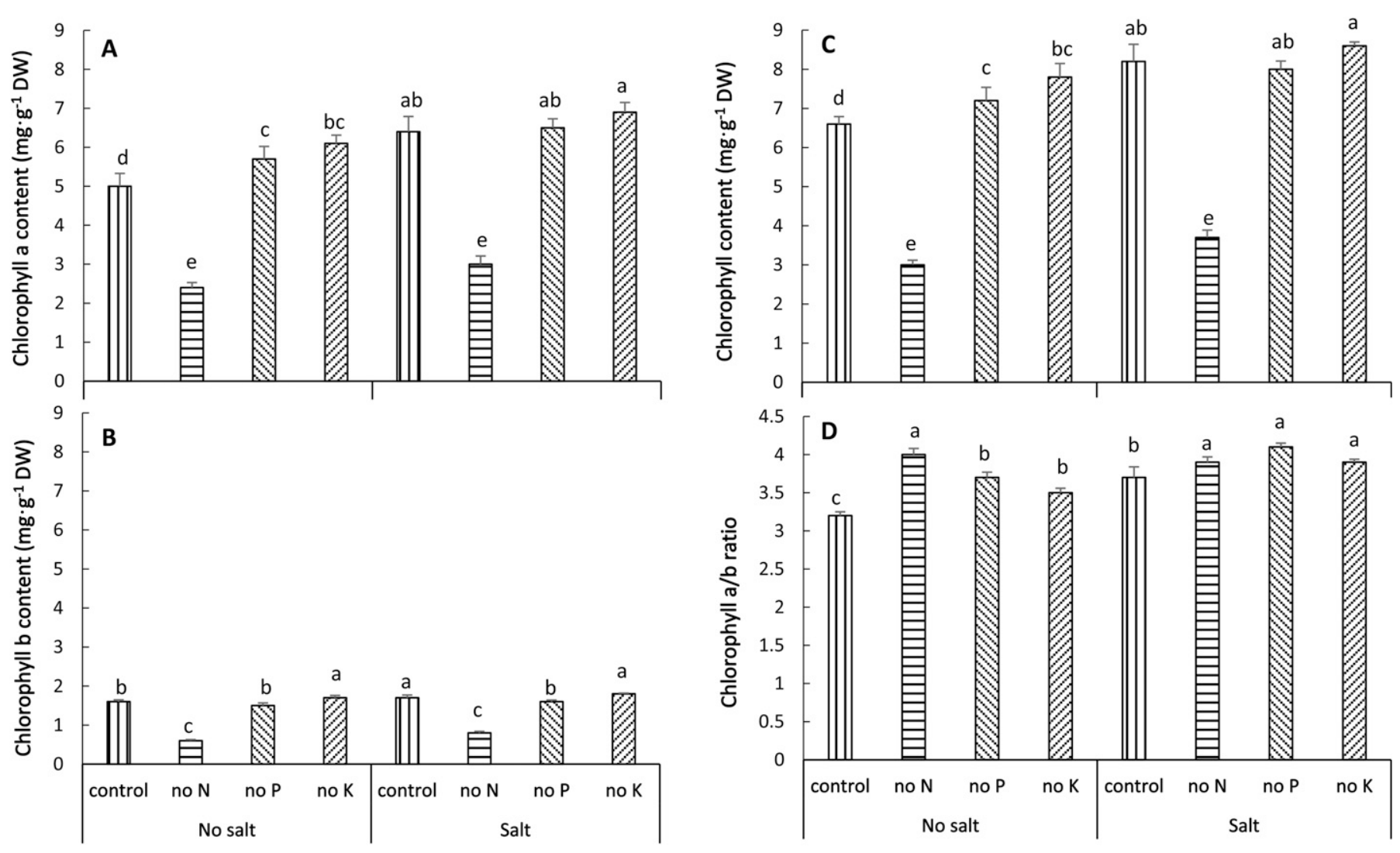

Fig. 3. Effect of salinity and nutrient deficiency on spinach leaf (A) chlorophyll a, (B) chlorophyll b, (C) total chlorophyll content, and (D) ratio of a:b 4 weeks after treatment. The values are means of eight replicates \pm SE. Different letters on top of bars indicate significant difference at $P \leq 0.05$ according to Student's $t$ test.

et al., 1995). DPPH (20 mg. $\left.\mathrm{L}^{-1}\right)$ was dissolved in $100 \%$ methanol. Sample extracts $(20 \mu \mathrm{L})$ were added to $2 \mathrm{~mL}$ DPPH solution, and the absorbance was determined at $515 \mathrm{~nm}$ before and after 6 min reaction. Trolox (6-hydroxy-2,5,7,8-tetramethylchroman-2carboxyl acid) standard curve was prepared. For FICA measurement, the reaction mixture contained $40 \mu \mathrm{L}$ extracts, $1.48 \mathrm{~mL}$ methanol, and $30 \mu \mathrm{L}$ of $2 \mathrm{~mm}$ ferrous chloride. After vortexing, $40 \mu \mathrm{L}$ of $5 \mathrm{~mm}$ ferrozine was added followed by vigorous mixing. After $4 \mathrm{~min}$, the absorbance of the ferrozine-ferrous ions complex was measured at $562 \mathrm{~nm}$ (Dinis et al., 1994). FICA was calculated as the absorbance difference between control and sample.

Statistical analysis. A complete randomized design was used for this experiment. Each biological replicate contained one pot and each treatment contained four replicate pots for each trial. Treatment means were separated by Student's $t$ test at the 0.05 level of probability using the JMP program (version 5; SAS Institute, Cary, NC). The interaction between the two trials was not significant, so data were pooled together.

\section{Results}

Growth AND Physiological ReSPONSES. Spinach growth was greatly inhibited by both salinity and nutrient deficiency. Under control nutrient treatment, salt stress decreased shoot FW and DW by $34 \%$ and $27 \%$, respectively (Fig. $1 \mathrm{~A}$ and B). Both P- and K-deficient treatments similarly reduced shoot FW and DW under both no-salt treatment (approximately $27 \%$ and $20 \%$ for $\mathrm{FW}$ and DW, respectively) and salt stress (approximately $20 \%$ and $14 \%$ for $\mathrm{FW}$ and DW, respectively) (Fig. 1A and B). Nitrogen deficiency greatly decreased shoot FW and DW, either without salt stress (by $85 \%$ and $79 \%$ for FW and DW, respectively) or with salt stress (by $68 \%$ and $61 \%$ for FW and DW, respectively).

Leaf RWC decreased under salt stress but was unaffected by nutrient deficiency under either no-salt treatment or salt stress (Fig. 2A). Salinity decreased SLA without nutrient deficiency and with $\mathrm{P}$ or $\mathrm{K}$ deficiency (Fig. 2B). Nitrogen deficiency decreased SLA irrespective of salinity treatment, while P or K deficiency similarly decreased SLA only under salt stress (Fig. 2B).

Under control nutrient conditions, salt stress significantly increased both chlorophyll a and $\mathrm{b}$ contents, total chlorophyll content, and the chlorophyll a:b ratio (Fig. 3A-D). Nitrogen deficiency greatly reduced chlorophyll a (by $52 \%$ and $56 \%$ under no-salt and salt stress, respectively) and chlorophyll b content (by $63 \%$ and 53\% under no-salt and salt stress, respectively) and increased the ratio of chlorophyll a:b over control nutrient conditions, regardless of salinity treatment (Fig. 3A, B, and D). Both $\mathrm{P}$ and $\mathrm{K}$ deficiencies enhanced chlorophyll a and total chlorophyll content without salt stress and increased chlorophyll a:b with or without salt stress (Fig. $3 \mathrm{~A}, \mathrm{C}$, and D).

Salinity increased spinach leaf $F_{v} / F_{m}$ and $Y(I I)$ under control nutrient conditions (Fig. 4A and B). Under no-salt conditions, $P$ deficiency increased $F_{v} / F_{m}$ and $Y(I I)$ while $N$ and $K$ deficiencies did not have any effect on them. Under salt stress, $\mathrm{N}$ deficiency reduced both $\mathrm{F}_{\mathrm{v}} / \mathrm{F}_{\mathrm{m}}$ and $\mathrm{Y}(\mathrm{II}), \mathrm{P}$ deficiency 

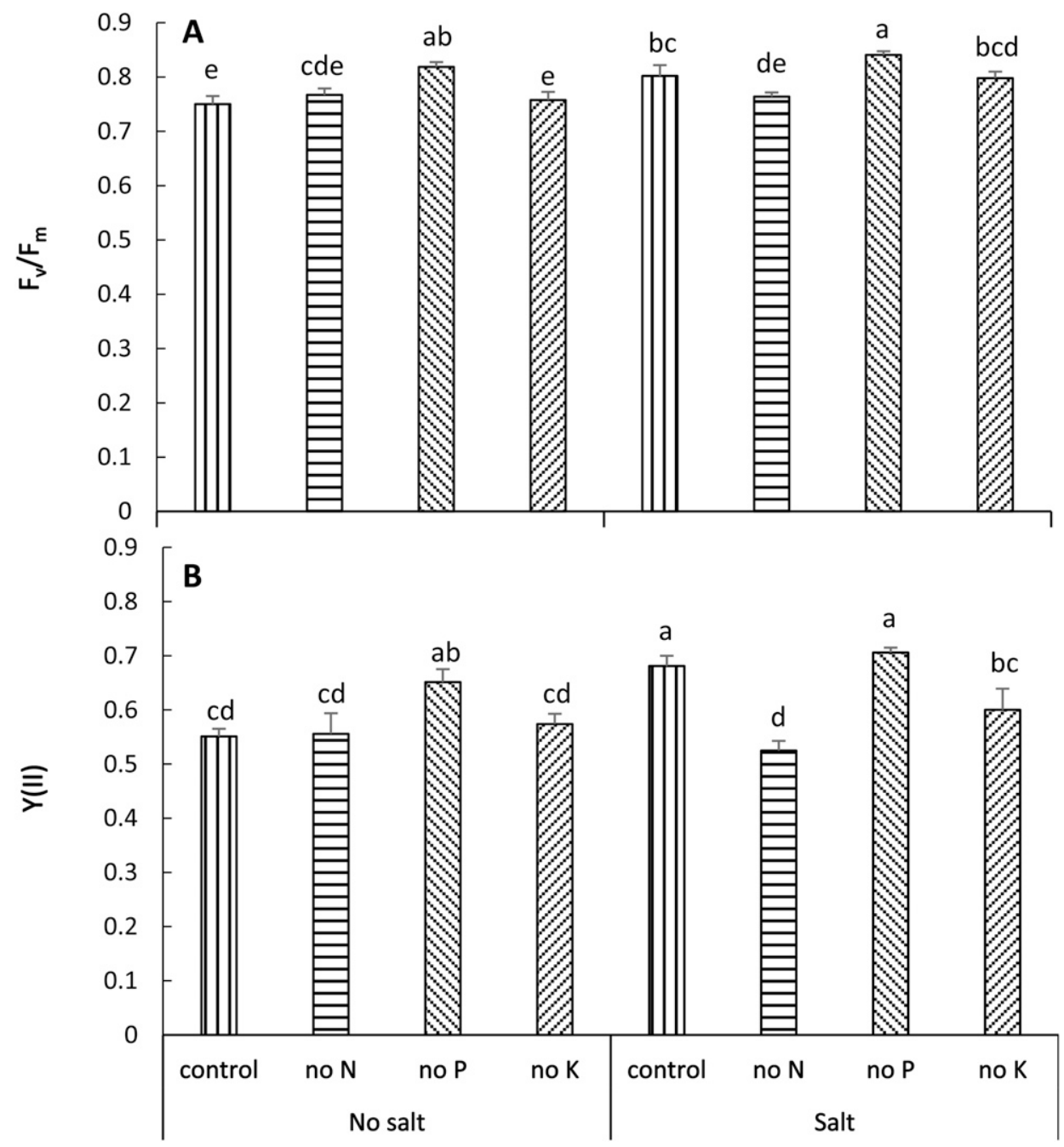

Fig. 4. Effect of salinity and nutrient deficiency on spinach leaf $(\mathbf{A})$ photochemical efficiency $\left(\mathrm{F}_{\mathrm{v}} / \mathrm{F}_{\mathrm{m}}\right)$ and $(\mathbf{B})$ photochemical yield [Y(II)] 4 weeks after treatment. The values are means of eight replicates \pm SE. Different letters on top of bars indicate significant difference at $P \leq 0.05$ according to Student's $t$ test.

Total antioxidant capacity increased under no-salt treatments with $\mathrm{N}$ or $\mathrm{K}$ deficiency (Fig. 6A). Salt stress decreased FICA not only under control nutrient treatments but also with $\mathrm{P}$ or $\mathrm{K}$ deficiency (Fig. 6B). Nitrogen deficiency greatly reduced FICA by $80 \%$ and $46 \%$ under no-salt and salt stress, respectively. Phosphorus deficiency decreased FICA under salt stress and $\mathrm{K}$ deficiency reduced FICA under no-salt conditions as well as under salt stress (Fig. 6B). Salt stress enhanced reducing power under control nutrient treatments, while nutrient deficiency increased reducing power under both no-salt and salt stress (Fig. 6C).

Both protein and amino acid contents were greatly reduced by $\mathrm{N}$ deficiency either with or without salt stress, and $\mathrm{P}$ deficiency decreased amino acid content under salt stress (Fig. 7A and B).

\section{Discussion}

Growth AND PHYSIOLOGICAL RESPONSES. Spinach growth was greatly inhibited by salinity as indicated by reduced shoot FW and DW. Salinity induces an ion-specific shoot growth inhibition caused by a disturbance in mineral nutrition, which might occur either as an excess or deficiency in mineral supply. Lazof and Bernstein (1999) found that $\mathrm{Ca}^{2+}$ transport to young leaves is sensitive to salinity and is

increased $F_{v} / F_{m}$, and $K$ deficiency decreased $Y(I I)$ (Fig. 4A and $\mathrm{B})$.

Nutritional VAlues. Under complete nutrient treatment, salt stress increased carotenoid content (Fig. 5A). Nitrogen deficiency greatly reduced carotenoid content either with (by $45 \%$ ) or without (by 50\%) salt stress, while $\mathrm{P}$ and $\mathrm{K}$ deficiencies increased carotenoid content without salt stress (Fig. 5A). Anthocyanin content was greatly enhanced under $\mathrm{N}$ deficiency by $145 \%$ and $88 \%$ under no-salt controls and under salt stress, respectively, but neither salt stress nor $\mathrm{P}$ or $\mathrm{K}$ deficiency had any influence on anthocyanin content (Fig. 5B).

Salt stress had no effect on total phenolic content under control nutrient conditions (Fig. 5C). Nitrogen deficiency greatly enhanced phenolic content by $66 \%$ and $22 \%$ for nosalt and salt stress, respectively, while $\mathrm{P}$ deficiency increased phenolic content under salt stress and $\mathrm{K}$ deficiency increased phenolic content under no-salt conditions (Fig. 5C). Under control nutrient treatments, salt stress increased flavonoid content (Fig. 5D). Nitrogen deficiency reduced flavonoid content by $14 \%$ and $36 \%$ for no-salt and salt stress, respectively, while $\mathrm{P}$ and $\mathrm{K}$ deficiencies enhanced flavonoid content under no-salt treatment (Fig. 5D). a key physiological response in the inhibition of lettuce leaf growth. In this study, salt stress decreased spinach leaf water content, which is consistent with previous studies in lettuce (Pérez-López et al., 2013; Shannon et al., 1983). Low leaf water content results in stomatal closure and loss of cell turgor pressure and cell expansion, leading to reduced photosynthetic rate and leaf area, and, therefore, growth inhibition (Taiz and Zeiger, 2012). Indeed, previous studies indicated that salt stress caused a reduction in stomatal and mesophyll conductance, which decreased chloroplastic $\mathrm{CO}_{2}$ concentrations in spinach and lettuce (Delfine et al., 1998, 1999; Downton et al., 1985; Eraslan et al., 2007; Robinson et al., 1983). This caused an inhibition of photosynthesis, which was not related to changes in biochemical and photochemical capacity, since salt stress did not result in decreased chlorophyll fluorescence or activity and content of ribulose-1,5-bisphosphate carboxylase/oxygenase (Rubisco) (Delfine et al., 1998).

Previous studies have found that spinach chlorophyll content was reduced by $\mathrm{NaCl}$ solution with high concentration of 200 or 172 mм (Delfine et al., 1998; Downton et al., 1985; Robinson et al., 1983), while chlorophyll fluorescence was unaffected (Delfine et al., 1998; Robinson et al., 1983). Eraslan et al. 

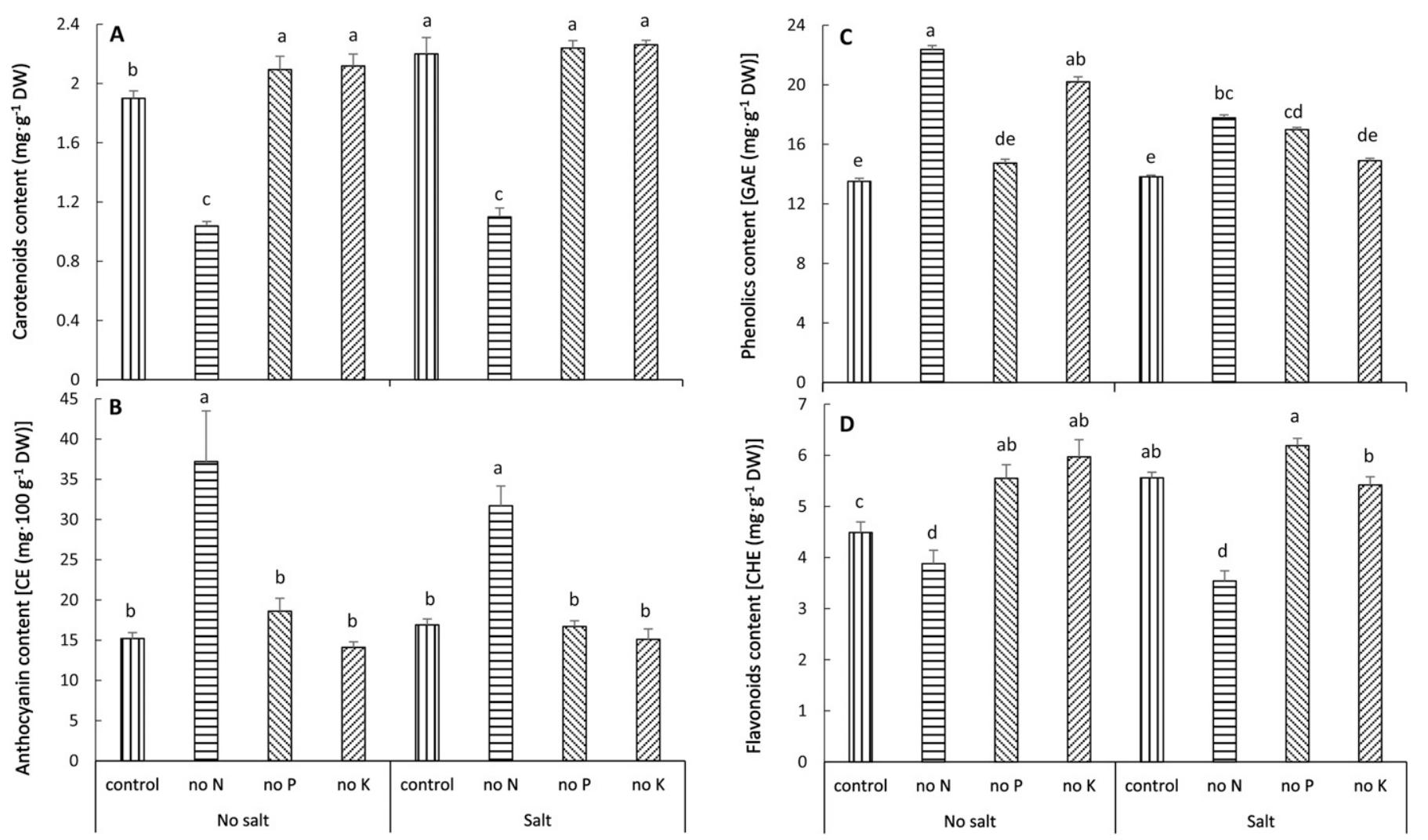

Fig. 5. Effect of salinity and nutrient deficiency on spinach leaf contents of (A) carotenoids, (B) anthocyanin, (C) phenolics, and (D) flavonoids 4 weeks after treatment. The values are means of eight replicates \pm SE. Different letters on top of bars indicate significant difference at $P \leq 0.05$ according to Student's $t$ test. CE $=$ cyanidin-3 glucoside equivalents; $\mathrm{CHE}=(+)$-catechin hydrate equivalents; $\mathrm{GAE}=$ gallic acid equivalents.

(2008) reported that application of $50 \mathrm{mmol} \mathrm{NaCl} / \mathrm{kg}$ as soil amendment did not alter chlorophyll content, but Kaya et al. (2002) reported that spinach chlorophyll content was reduced by $60 \mathrm{~mm} \mathrm{NaCl}$ solution. The present study found that mild salt stress increased spinach chlorophyll content and fluorescence. The inconsistencies among these studies might be due to differences in salinity severity, period, and application methods. In our study, salt stress increased chlorophyll a:b ratio, suggesting that the contents of chlorophyll $\mathrm{a}$ and $\mathrm{b}$ did not respond to salinity synchronously. High chlorophyll a:b indicated more chlorophyll a proteins of photosystem II and I and less light harvesting complex II and I (Anderson, 1986). In the present study, growth inhibition caused by salt stress was not related to changes in photochemical capacity.

In the present study, salt stress decreased spinach SLA, a function of leaf dry matter content and thickness. Increased leaf thickness is often observed as a result of salt stress in spinach (Coughlan and Jones, 1980; Downton et al., 1985; Robinson et al., 1983) and other species (Heuer and Plaut, 1981; Longstreth and Nobel, 1979), although Delfine et al. (1998) found that leaf thickness was lower in salt-stressed spinach than in control treatments. Reduction of SLA is assumed to improve water use efficiency, because thicker leaves usually have a greater photosynthetic capacity than thinner leaves (Craufurd et al., 1999; Liu and Stützel, 2004; Wright et al., 1994). The reduced SLA in this study might result from reduced water content under salt stress. Drought stress is also known to decrease SLA (Liu and Stützel, 2004; Marcelis et al., 1998). A decrease in SLA under water deficit may be due to the different sensitivity of photosynthesis and leaf expansion, since water deficit stress reduces leaf expansion earlier than photosynthesis (Jensen et al., 1996; Tardieu et al., 1999).

Nitrogen deficiency reduced spinach growth under both nosalt and salt stress in the present study. The reduced plant growth was not related to water relations since $\mathrm{N}$ deficiency did not alter leaf RWC regardless of salinity treatment. The most general symptom of $\mathrm{N}$ deficiency is leaf chlorosis and growth retardation. In this study, $\mathrm{N}$ deficiency greatly decreased chlorophyll content (more than 50\%) and increased chlorophyll $a: b$ irrespective of salt stress. Chlorophyll fluorescence in plants grown under $\mathrm{N}$ deficiency was reduced under both no-salt and salt stress treatments. Nitrogen deficiency can modify enzyme activities and metabolite contents (Lemaître et al., 2008; Zhang et al., 2010). It enhanced sugar accumulation while reducing amino acid content (Lemaître et al., 2008; Wei et al., 2015) and hastened leaf senescence due to high C:N ratio (Wingler et al., 2006). After prolonged $\mathrm{N}$ starvation, the breakdown of enzymes and nucleic acids starts to occur (Crafts-Brandner et al., 1998). Eventual breakdown of Rubisco resulted in a decreased photosynthesis capacity and ultimately inhibited plant growth (Walker et al., 2001). Similarly as Stagnari et al. (2015) reported in lettuce, $\mathrm{N}$ deficiency decreased SLA in this study, which could improve resource use efficiency.

In the present study, $\mathrm{P}$ and $\mathrm{K}$ deficiencies similarly inhibited spinach shoot growth under no-salt or salt stress, reduced SLA under salt stress, and increased chlorophyll content under nosalt treatments. Phosphorus deficiency enhanced $F_{v} / F_{m}$ under both no-salt and salt stress, and increased $\mathrm{Y}(\mathrm{II})$ under no-salt 


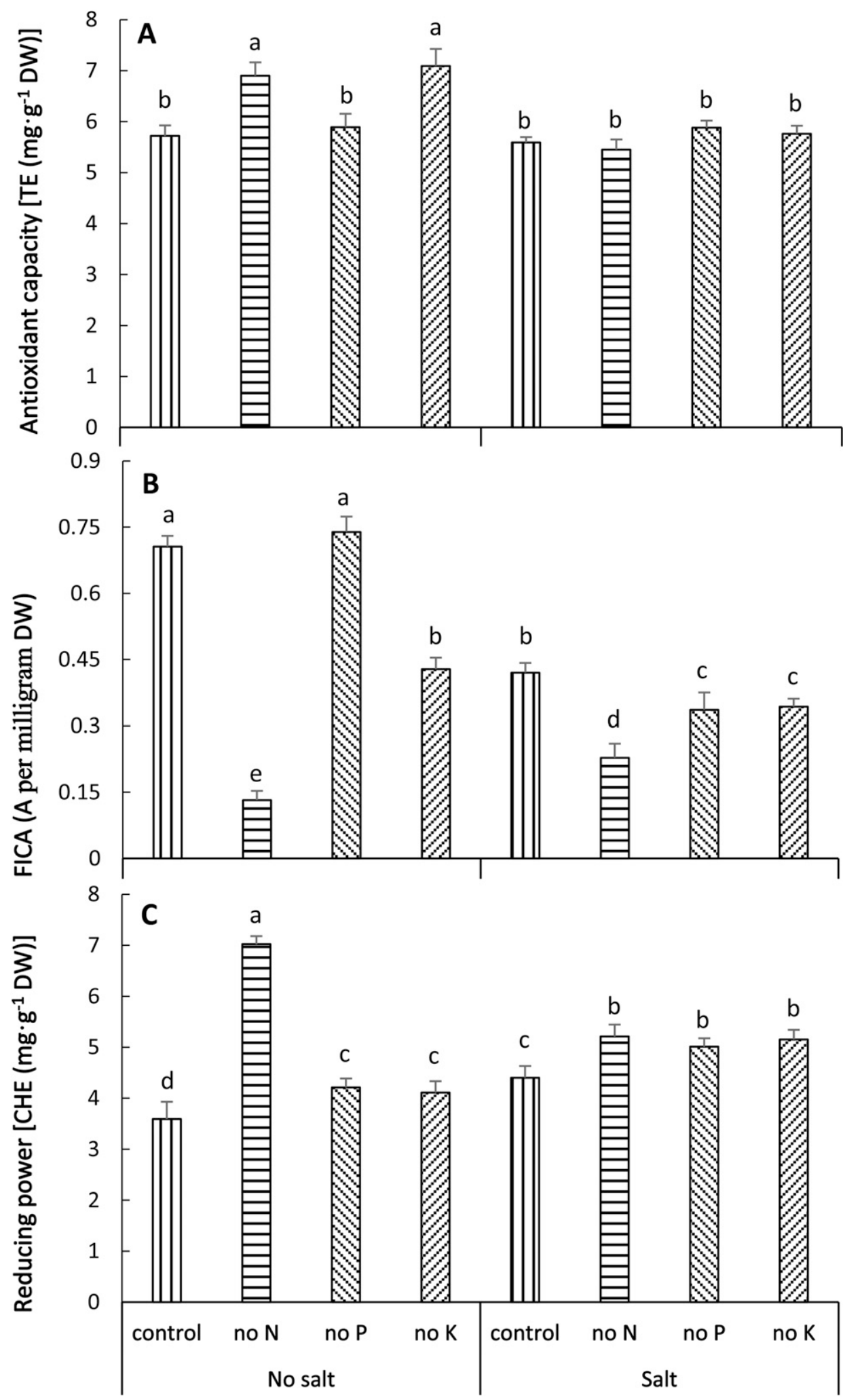

Fig. 6. Effect of salinity and nutrient deficiency on spinach leaf (A) total antioxidant capacity, (B) ferrous ion chelating ability (FICA), and (C) reducing power 4 weeks after treatment. The values are means of eight replicates \pm SE. FICA was calculated as the absorbance difference (A) between control and sample per milligram dry weight (DW). Different letters on top of bars indicate significant difference at $P \leq 0.05$ according to Student's $t$ test. $\mathrm{CHE}=(+)$-catechin hydrate equivalents; $\mathrm{TE}=$ trolox equivalents. conditions. Potassium deficiency only reduced Y(II) under salt stress. Previous studies indicate that $\mathrm{P}$ deficiency reduced stomatal conductance and photosynthetic rate in spinach and pepper (Capsicum annuum L.) (Davies et al., 1999; Dietz and Foyer, 1986) and decreased chlorophyll content and $\mathrm{F}_{\mathrm{v}} / \mathrm{F}_{\mathrm{m}}$ in sunflower [Helianthus annuus L. (Plesnićar et al., 1994)] and creeping bentgrass [Agrostis stolonifera L. (Zhang et al., 2010)]. But P deficiency did not alter chlorophyll content and $\mathrm{F}_{\mathrm{v}} / \mathrm{F}_{\mathrm{m}}$ of common bean [Phaseolus vulgaris L. (Lima et al., 1999)]. Similarly, this study indicated that photochemistry was not damaged by $\mathrm{P}$ deficiency in spinach. The inconsistency might be due to differences in species, severity, and/ or period of $\mathrm{P}$ deficiency. In rough lemon (Citrus volkameriana Ten. \& Pasq), K-deficient plant produced less biomass but did not develop leaf chlorosis (Lavon et al., 1999). However, K deficiency caused dramatically low chlorophyll content in cotton [Gossypium hirsutum L. (Zhao et al., 2001)]. This indicates that there are pronounced differences among species in crop responses to $\mathrm{K}$ deficiency. In this study, both $\mathrm{P}$ and $\mathrm{K}$ deficiencies reduced spinach growth to a lesser extent than $\mathrm{N}$ deficiency, which is consistent with other studies in okra [Abelmoschus esculentus L. (Papenfus et al., 2013)] and lettuce (Galieni et al., 2015). This indicates the prevalent role of $\mathrm{N}$ in plant energy metabolism such as photosynthesis and transpiration. A large portion of $\mathrm{N}$ in plants is associated with energy metabolism and a small part is incorporated in structural cell components, while $\mathrm{P}$ and $\mathrm{K}$ constitute a large part of cell components.

Nutritional values. Carotenoids have long been recognized as essential nutrients and important health-beneficial compounds (Fraser and Bramley, 2004). Phenolics are a class of secondary metabolites that play a key role as antioxidants. The most important group of phenolics in plants is flavonoids, which have attracted considerable interest due to their broad spectrum of biological effects such as antioxidative, antiinflammatory, vasorelaxant, antimicrobial, and 


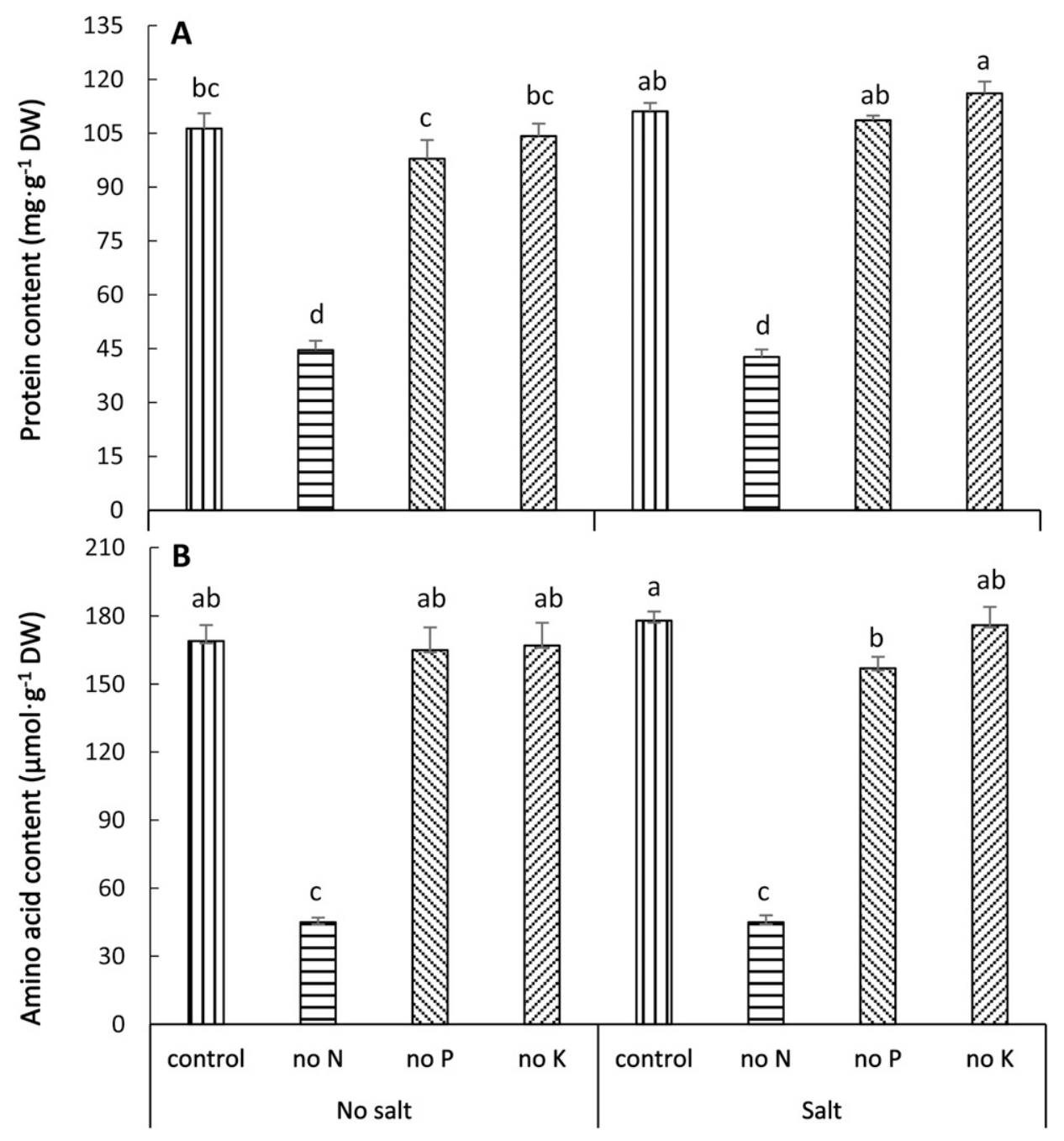

Fig. 7. Effect of salinity and nutrient deficiency on spinach leaf contents of (A) protein and (B) amino acid 4 weeks after treatment. The values are means of eight replicates \pm SE. Different letters on top of bars indicate significant difference at $P \leq 0.05$ according to Student's $t$ test.

antiviral and their anticarcinogenic and antimutagenic activities (Guo et al., 2011; Maimoona et al., 2011). Anthocyanin is a group of flavonoids with exceptionally good scavenging activities. Under control nutrient treatments, salt stress increased carotenoid and flavonoid contents, but had no effect on the content of anthocyanins and phenolics. Application of $50 \mathrm{mmol} \mathrm{NaCl} / \mathrm{kg}$ soil increased spinach total antioxidant capacity without changing anthocyanin content (Eraslan et al., 2008). In lettuce, salt stress was also reported to increase total antioxidant capacity (Pérez-López et al., 2013) and carotenoid content but did not alter phenolic content (Kim et al., 2008). The inconsistency might be due to differences in species, salinity severity or period, and application methods.

Interestingly, leaf FICA decreased significantly under salt stress in the present study. Ferrous ion chelation is another indirect mechanism of antioxidant activity. Although iron is an essential element, excess iron may lead to high levels of reactive oxygen species. Ferrous ion chelation can afford protection against oxidative damage (Huang, 2003). Polysaccharides, peptides, proteins, oleoresins, and saponins have been reported to chelate ferrous ions (Gülçin et al., 2006; Wang et al., 2009). A previous study indicated that drought stress also reduced spinach FICA ( $\mathrm{Xu}$ and Leskovar, 2015). Our results suggest that spinach nutritional quality could be negatively affected by reduced FICA under salt stress. Besides hydrogen donation, another import mechanism by which polyphenols scavenge reactive oxygen species is through electron transfer. In this study, salt stress enhanced reducing power, which is consistent with the increase of flavonoid content and might positively alter spinach nutritional quality.

In the present study, $\mathrm{N}$ deficiency increased the reducing power and the contents of anthocyanin and total phenolics while it decreased the contents of carotenoids and flavonoids, irrespective of salinity treatment. However, it only increased antioxidant capacity without salt stress. Inconsistent effects of $\mathrm{N}$ starvation on lettuce nutritional value have been reported. Similar to the present study, Coria-Cayupán et al. (2009) and Galieni et al. (2015) found that low $\mathrm{N}$ level increased phenolic compounds and antioxidant capacity; however, Stagnari et al. (2015) reported that antioxidant capacity was not altered by $\mathrm{N}$ deficiency though it increased phenolic compounds. Low N supply was reported to increase phenolic and flavonoid compounds in tomato leaves, but no significant variation was observed in fruit (Bénard et al., 2009; Stewart et al., 2001). The induction of many enzymes involved in phenylpropanoid pathway in plant leaves was reported in response to reduced $\mathrm{N}$ supply (Bongue-Bartelsman and Phillips, 1995; Fritz et al., 2006).

Phosphorus deficiency increased the total phenolic content under salt stress and the contents of carotenoids and flavonoids irrespective of salt treatment in the present study. However, it had no effects on antioxidant capacity. Phosphorus deficiency also reduced FICA and amino acid content under salt stress and increased reducing power regardless of salinity treatment. In lettuce, $\mathrm{P}$ deficiency did not alter phenolic content and antioxidant capacity (Galieni et al., 2015). Also, it did not increase flavonoid content in tomato leaves (Stewart et al., 2001). In this study, K deficiency increased antioxidant capacity and the contents of carotenoid, total phenolic, and flavonoid under non-salt conditions, but decreased FICA and increased reducing power regardless of salt treatment. It had no influences on the contents of protein and amino acid, which is consistent with results in rough lemon (Lavon et al., 1999).

In summary, the mild salt stress simulated in this study inhibited spinach growth by water deficit, although it improved photochemistry. Salt stress, when applied along with full 
nutrient conditions, reduced FICA, enhanced flavonoid and carotenoid contents, and increased the reducing power. Nitrogen deficiency greatly inhibited spinach growth but positively influenced nutritional quality by enhancing phenolic and anthocyanin contents, especially under no-salt conditions. Phosphorus deficiency inhibited growth even though it improved photochemistry and the nutritional value by a high reducing power. Potassium deficiency appears to reduce spinach growth as well, but positively influenced nutritional value by increasing the antioxidant capacity, reducing power, and amounts of carotenoids, phenolics, and flavonoids, especially under no-salt conditions. The content of total phenolics or flavonoids does not necessarily indicate the level of antioxidant capacity in spinach. These results suggest that the nutritional value of spinach could be improved with only moderately or slightly reduced yield through cultural practices that impose either low fertilizer levels or slight salt stress.

\section{Literature Cited}

Anderson, J.M. 1986. Photoregulation of the composition, function, and structure of thylakoid membranes. Annu. Rev. Plant Physiol. 37:93-136.

Apetrei, C.L., C. Tuchilus, A.C. Aprotosoaie, A. Oprea, K.E. Malterud, and A. Miron. 2011. Chemical, antioxidant and antimicrobial investigations of Pinus cembra L. bark and needles. Mol. 16:77737788 .

Barr, H.D. and P.E. Weatherley. 1962. A re-examination of the relative turgidity technique for estimating water deficit in leaves. Austral. J. Biol. Sci. 15:413-428.

Bénard, C., H. Gautier, F. Bourgaud, D. Grasselly, B. Navez, C. CarisVeyrat, M. Weiss, and M. Génard. 2009. Effects of low nitrogen supply on tomato (Solanum lycopersicum) fruit yield and quality with special emphasis on sugars, acids, ascorbate, carotenoids, and phenolic compounds. J. Agr. Food Chem. 57:4112-4123.

Bergman, M., L. Varshavsky, H.E. Gottlieb, and S. Grossman. 2001. The antioxidant activity of aqueous spinach extract: Chemical identification of active fractions. Phytochemisty 58:143-152.

Bongue-Bartelsman, M. and D.A. Phillips. 1995. Nitrogen stress regulates gene expression of enzymes in the flavonoid biosynthetic pathway of tomato. Plant Physiol. Biochem. 33:539-546.

Borghesi, E., M.L. González-Miret, M.L. Escudero-Gilete, F. Malorgio, F.J. Heredia, and A.J. Meléndez-Martínez. 2011. Effects of salinity stress on carotenoids, anthocyanins, and color of diverse tomato genotypes. J. Agr. Food Chem. 59:11676-11682.

Bradford, M.M. 1976. A rapid and sensitive method for the quantitation of microgram quantities of protein utilizing the principle of protein-dye binding. Anal. Biochem. 72:248-254.

Brand-Williams, W., M.E. Cuvelier, and C. Berset. 1995. Use of a free radical method to evaluate antioxidant activity. LebensmittelWissenschaft und Technologie 28:25-30.

Connor, A.M., J.J. Luby, and C.B.S. Tong. 2002. Variability in antioxidant activity in blueberry and correlations among different antioxidant activity assays. J. Amer. Soc. Hort. Sci. 127:238-244.

Coria-Cayupán, Y.S., M.I. Sánchez de Pinto, and M.A. Nazareno. 2009. Variations in bioactive substance contents and crop yields of lettuce (Lactuca sativa L.) cultivated in soils with different fertilization treatments. J. Agr. Food Chem. 57:10122-10129.

Coughlan, S.J. and R.G.W. Jones. 1980. Some responses of Spinacea oleracea to salt stress. J. Expt. Bot. 31:883-893.

Crafts-Brandner, S.J., R. Hölzer, and U. Feller. 1998. Influence of nitrogen deficiency on senescence and the amounts of RNA and proteins in wheat leaves. Physiol. Plant. 102:192-200.

Craufurd, P.Q., T.R. Wheeler, R.H. Ellis, R.J. Summerfield, and J.H. Williams. 1999. Effect of temperature and water deficit on water-use efficiency, carbon isotope discrimination, and specific leaf area in peanut. Crop Sci. 39:136-142.
Davies, F.T., S.A. Duray, L. Phavaphutanon, and R.S. Stahl. 1999. Influence of phosphorus on gas exchange and plant growth of two morphologically distinct types of Capsicum annuum. Photosynthetica 39:99-106.

Delfine, S., A. Alvino, M.C. Villani, and F. Loreto. 1999. Restrictions to carbon dioxide conductance and photosynthesis in spinach leaves recovering from salt stress. Plant Physiol. 119:1101-1106.

Delfine, S., A. Alvino, M. Zacchini, and F. Loreto. 1998. Consequences of salt stress on conductance to $\mathrm{CO}_{2}$ diffusion, Rubisco characteristics and anatomy of spinach leaves. Aust. J. Plant Physiol. 25:395-402.

Dewanto, V., X. Wu, K.K. Adom, and R.H. Liu. 2002. Thermal processing enhances the nutritional value of tomatoes by increasing total antioxidant activity. J. Agr. Food Chem. 50:3010-3014.

Dietz, K.J. and C. Foyer. 1986. The relationship between phosphate status and photosynthesis in leaves. Planta 167:376-381.

Dinis, T.C.P., V.M.C. Madeira, and M.L.M. Almeida. 1994. Action of phenolic derivatives (acetoaminophen, salycilate and 5-aminosalycilate) as inhibitors of membrane lipid peroxidation and as peroxyl radical scavengers. Arch. Biochem. Biophys. 315:161-169.

Downton, W.J.S., W.J.R. Grant, and S.P. Robinson. 1985. Photosynthetic and stomatal responses of spinach leaves to salt stress. Plant Physiol. 77:85-88.

Edenharder, R., G. Keller, K.L. Platt, and K.K. Unger. 2001. Isolation and characterization of structurally novel antimutagenic flavonoids from spinach (Spinacia oleracea). J. Agr. Food Chem. 49:27672773.

Eraslan, F., A. Inal, D.J. Pilbeam, and A. Gunes. 2008. Interactive effects of salicylic acid and silicon on oxidative damage and antioxidant activity in spinach (Spinacia oleracea L. cv. Matador) grown under boron toxicity and salinity. Plant Growth Regulat. 55:207-219.

Eraslan, F., A. Inal, O. Savasturk, and A. Gunes. 2007. Changes in antioxidative system and membrane damage of lettuce in response to salinity and boron toxicity. Sci. Hort. 114:5-10.

Evans, G.C. 1972. The quantitative analysis of plant growth. Univ. California Press, Berkeley, CA.

Flowers, T.J., H.K. Galal, and L. Bromham. 2010. Evolution of halophytes: Multiple origins of salt tolerance in land plants. Funct. Plant Biol. 37:604-612.

Fraser, P.D. and P.M. Bramley. 2004. The biosynthesis and nutritional uses of carotenoids. Prog. Lipid Res. 43:228-265.

Fritz, C., N. Palacios-Rojas, R. Feil, and M. Stitt. 2006. Regulation of secondary metabolism by the carbon-nitrogen status in tobacco: Nitrate inhibits large sectors of phenylpropanoid metabolism. Plant J. 46:533-548.

Galieni, A., C.D. Mattia, M.D. Gregorio, S. Speca, D. Mastrocola, M. Pisante, and F. Stagnari. 2015. Effects of nutrient deficiency and abiotic environmental stresses on yield, phenolic compounds and antiradical activity in lettuce (Lactuca sativa L.). Sci. Hort. 187:93-101.

Gülçin, I., V. Mshvildadze, A. Gepdiremen, and R. Elias. 2006. The antioxidant activity of a triterpenoid glycoside isolated from the berries of Hedera colchica: 3-O-( $\beta$-D-glucopyranosyl)-hederagenin. Phytother. Res. 20:130-134.

Guo, T., L. Wei, J. Sun, C. Hou, and L. Fan. 2011. Antioxidant activities of extract and fractions from Tuber indicum Cooke \& Massee. Food Chem. 127:1634-1640.

Halvin, J.L., J.D. Beaton, S.L. Tisdale, and W.L. Nelson. 2005. Soil fertility and fertilizers. 7th ed. Pearson Educ., Upper Saddle River, NJ.

Heuer, B. and Z. Plaut. 1981. Carbon dioxide fixation and ribulose1,5-bisphosphate carboxylase activity in intact leaves of sugar beet plants exposed to salinity and water stress. Ann. Bot. (Lond.) 48:261-268.

Hoagland, D.R. and D.I. Arnon. 1950. The water-culture method for growing plants without soil. California Agr. Expt. Sta. Circ. 247.

Huang, X. 2003. Iron overload and its association with cancer risk in humans: Evidence for iron as a carcinogenic metal. Mutat. Res. 533:153-171. 
Jensen, C.R., V.O. Mogensen, G. Mortensen, M.N. Andersen, J.K Schjoerring, J.H. Thage, and J. Koribidis. 1996. Leaf photosynthesis and drought adaptation in field-grown oilseed rape (Brassica napus L.). Austral. J. Plant Physiol. 23:631-644.

Kaya, C., D. Higgs, and E. Sakar. 2002. Response of two leafy vegetables grown at high salinity to supplementary potassium and phosphorus during different growth stages. J. Plant Nutr. 25:26632676.

Kim, H.J., J.M. Fonseca, J.H. Choi, C. Kubota, and D.Y. Kwon. 2008. Salt in irrigation water affects the nutritional and visual properties of romaine lettuce (Lactuca sativa L.). J. Agr. Food Chem. 56:37723776.

Langdale, G.W., J.R. Thomas, and T.G. Littleton. 1971. Influence of soil salinity and nitrogen fertilizer on spinach growth. J. Rio Grande Valley Hort. Soc. 25:61-66.

Lavon, R., R. Salomon, and E.E. Goldschmidt. 1999. Effect of potassium, magnesium, and calcium deficiencies on nitrogen constituents and chloroplast components in citrus leaves. J. Amer. Soc. Hort. Sci. 124:158-162.

Lawlor, D.W. 2002. Limitation to photosynthesis in water-stressed leaves: Stomata vs. metabolism and the role of ATP. Ann. Bot. (Lond.) 89:871-885.

Lazof, D.B. and N. Bernstein. 1999. Effects of salinization on nutrient transport to lettuce leaves: Consideration of leaf developmental stage. New Phytol. 144:85-94.

Lemaitre, T., L. Gaufichon, S. Boutet-Mercey, A. Christ, and C. Masclaux-Daubresse. 2008. Enzymatic and metabolic diagnostic of nitrogen deficiency in Arabidopsis thaliana Wassileskija accession. Plant Cell Physiol. 49:1056-1065.

Lichtenthaler, H.K. 1987. Chlorophylls and carotenoids-pigments of photosynthetic biomembranes. Methods Enzymol. 148:350-382.

Lima, J.D., P.R. Mosquim, and F.M. Da Matta. 1999. Leaf gas exchange and chlorophyll fluorescence parameters in Phaseolus vulgaris as affected by nitrogen and phosphorus deficiency. Photosynthetica 37:113-121.

Liu, F. and H. Stützel. 2004. Biomass partitioning, specific leaf area, and water use efficiency of vegetable amaranth (Amaranthus spp.) in response to drought stress. Sci. Hort. 102:15-27.

Longstreth, D.J. and P.S. Nobel. 1979. Salinity effects on leaf anatomy consequences for photosynthesis. Plant Physiol. 63:700-703.

Maimoona, A., I. Naeem, Z. Saddiqe, and K. Jameel. 2011. A review on biological, nutraceutical and clinical aspects of French maritime pine bark extract. J. Ethnopharmacol. 133:261-277.

Marcelis, L.F.M., E. Heuvelink, and J. Goudriaan. 1998. Modelling biomass production and yield of horticultural crops: A review. Sci. Hort. 74:83-111.

Marschner, H. 1995. Mineral nutrition of higher plants. Academic Press, London, UK.

Oh, N.M., E.E. Carey, and C.B. Rajashekar. 2009. Environmental stresses induce health-promoting phytochemicals in lettuce. Plant Physiol. Biochem. 47:578-583.

Orcutt, D.M. and E.T. Nilsen. 2000. The physiology of plants under stress: Soil and biotic factors. Wiley, Hoboken, NJ.

Osawa, T. 1963. Studies on the salt tolerance of vegetable crops with special reference to osmotic effects and specific ion effects. J. Jpn. Soc. Hort. Sci. 32:211-223.

Pandjaitan, N., L.R. Howard, T. Morelock, and M.I. Gil. 2005. Antioxidant capacity and phenolic content of spinach as affected by genetics and maturation. J. Agr. Food Chem. 53:8618-8623.

Papenfus, H.B., M.G. Kulkarni, W.A. Stirk, J.F. Finnie, and J. Van Staden. 2013. Effect of a commercial seaweed extract $\left(\right.$ Kelpak $\left.^{\circledR}\right)$ and polyamines on nutrient-deprived (N, P and K) okra seedlings. Sci. Hort. 151:142-146.

Pasternak, D. and Y. De Malach. 1994. Handbook of plant and crop stress. Marcel Dekker, New York, NY.

Pérez-López, U., J. Miranda-Apodaca, A. Muñoz-Rueda, and A. Mena-Petite. 2013. Lettuce production and antioxidant capacity are differentially modified by salt stress and light intensity under ambient and elevated $\mathrm{CO}_{2}$. J. Plant Physiol. 170:1517-1525.

Plesnićar, M., R. Kastori, N. Petrović, and D. Panković. 1994. Photosynthesis and chlorophyll fluorescence in sunflower (Helianthus annuus L.) leaves as affected by phosphorus nutrition. J. Expt. Bot. 45:919-924.

Qadir, M., A. Tubeileh, J. Akhtar, A. Larbi, P.S. Minhas, and M.A. Khan. 2008. Productivity enhancement of salt-affected environments through crop diversification. Land Degrad. Dev. 19:429-453.

Robinson, R.P., W.J.S. Downton, and J.A. Millhouse. 1983. Photosynthesis and ion content of leaves and isolated chloroplasts of saltstressed spinach. Plant Physiol. 73:238-242.

Ruan, C.J., J.A.T. da Silva, S. Mopper, P. Qin, and S. Lutts. 2010. Halophyte improvement for a salinized world. Crit. Rev. Plant Sci. 29:329-359.

Shannon, M.C. and C.M. Grieve. 1999. Tolerance of vegetable crops to salinity. Sci. Hort. 78:5-38.

Shannon, M.C., J.D. McCreight, and J.H. Draper. 1983. Screening tests for salt tolerance in lettuce. J. Amer. Soc. Hort. Sci. 108:225-230.

Slinkard, K. and V.L. Singleton. 1997. Total phenol analysis: Automation and comparison with manual methods. Amer. J. Enol. Viticult. 28:49-55.

Stagnari, F., A. Galieni, and M. Pisante. 2015. Shading and nitrogen management affect quality, safety and yield of greenhouse-grown leaf lettuce. Sci. Hort. 192:70-79.

Stewart, A.J., W. Chapman, G.I. Jenkins, I. Graham, T. Martin, and A. Crozier. 2001. The effect of nitrogen and phosphorus deficiency on flavonol accumulation in plant tissues. Plant Cell Environ. 24:11891197.

Taiz, L. and E. Zeiger. 2012. Plant physiology. Sinauer Assoc., Sunderland, MA.

Tardieu, F., C. Granier, and B. Muller. 1999. Modelling leaf expansion in a fluctuating environment: Are changes in specific leaf area a consequence of changes in expansion rate? New Phytol. 143:33-43.

Walker, R.L., I.G. Burns, and J. Moorby. 2001. Responses of plant growth rate to nitrogen supply: A comparison of relative addition and $\mathrm{N}$ interruption treatments. J. Expt. Bot. 52:309-317.

Wang, T., R. Jónsdóttir, and G. Ólafsdóttir. 2009. Total phenolic compounds, radical scavenging and metal chelation of extracts from Icelandic seaweeds. Food Chem. 116:240-248.

Wang, M., Q. Zheng, Q. Shen, and S. Guo. 2013. The critical role of potassium in plant stress response. Intl. J. Mol. Sci. 14:7370-7390.

Wei, M., A. Zhang, H. Li, Z. Tang, and X. Chen. 2015. Growth and physiological response to nitrogen deficiency and re-supply in leafvegetable sweetpotato (Ipomoea batatas Lam). HortScience 50:754758 .

Wingler, A., S. Purdy, J.A. MacLean, and N. Pourtau. 2006. The role of sugars in integrating environmental signals during the regulation of leaf senescence. J. Expt. Bot. 57:391-399.

Wright, G.C., R.C.N. Rao, and G.D. Farquhar. 1994. Water-use efficiency and carbon isotope discrimination in peanuts under water deficit conditions. Crop Sci. 34:92-97.

$\mathrm{Xu}, \mathrm{C}$. and D.I. Leskovar. 2015. Effects of A. nodosum seaweed extracts on spinach growth, physiology and nutrition value under drought stress. Sci. Hort. 183:39-47.

Yokoyama, S. and J.I. Hiramatsu. 2003. A modified ninhydrin reagent using ascorbic acid instead of potassium cyanide. J. Biosci. Bioeng. 95:204-205.

Zhang, Y., C. Liang, Y. Xu, T. Gianfagna, and B. Huang. 2010. Effects of ipt gene expression on leaf senescence induced by nitrogen or phosphorus deficiency in creeping bentgrass. J. Amer. Soc. Hort. Sci. 135:108-115.

Zhao, D., D.M. Oosterhuts, and C.W. Bednarz. 2001. Influence of potassium deficiency on photosynthesis, chlorophyll content, and chloroplast ultrastructure of cotton plants. Photosynthetica 39:103109. 